\title{
Validation of a Hospital Clinical Pharmacy Workforce Calculator: A methodology for Pharmacy?
}

\author{
Ruth Bednall ${ }^{1}$, Simon White ${ }^{2}$, Elizabeth Mills ${ }^{3}$, and Susan Thomson ${ }^{1}$ \\ ${ }^{1}$ University Hospitals of North Midlands NHS Trust \\ ${ }^{2}$ Keele University \\ ${ }^{3}$ University College London
}

August 22, 2020

\begin{abstract}
Abstract Background The benefits of hospital clinical pharmacy services are well established, though staff numbers required for its delivery have not been well described, leading to variation in pharmacy staffing between hospitals. The need to identify a consistent, objective method of determining staffing levels was recognised at a UK University Hospital and a Clinical Pharmacy Workforce Calculator (CPWC) was developed. Objective To report on the validation of the CPWC across acute hospital settings in Great Britain. Method Using the World Health Organisation's Workload Indicators of Staffing Need (WISN) methodology, a two-round Delphi consensus study with an Expert Panel of UK hospital pharmacy managers was undertaken to develop the Activity Standard for pharmaceutical care and to identify the time unavailable for clinical work inherent in employing staff. Consenting Panel members then tested the CPWC by calculating the staff resource required for three staffing scenarios to determine whether it could be reliably used by different operators. Results Thirty-six participants consented to participate, and data was returned from 22 participants (61\%) of whom $20(56 \%)$ supplied analysable data. Consensus was achieved on the tasks required for pharmaceutical care delivery, the mean time each takes, the frequency of completion and the unavailable time in the employment of each grade of staff identified. The CPWC uses this data in an algorithm to calculate staffing requirements. Eleven participants (55\%) tested the CPWC and analysis of their responses showed that 31 of 33 (94\%) calculations were accurately completed using the CPWC. Conclusion This study has defined the WISN Activity Standard for pharmaceutical care delivery to hospital inpatients and validated the CPWC for acute medical and surgical hospital settings. The CPWC offers hospital pharmacy managers a useful tool to negotiate adequate staffing to deliver pharmaceutical care and its development methodology could be applied widely in pharmacy practice internationally.
\end{abstract}

Validation of a Hospital Clinical Pharmacy Workforce Calculator: A methodology for Pharmacy?

\section{Abstract \\ Background}

The benefits of hospital clinical pharmacy services are well established, though staff numbers required for its delivery have not been well described, leading to variation in pharmacy staffing between hospitals. The need to identify a consistent, objective method of determining staffing levels was recognised at a UK University Hospital and a Clinical Pharmacy Workforce Calculator (CPWC) was developed.

\section{Objective}

To report on the validation of the CPWC across acute hospital settings in Great Britain.

\section{Method}


Using the World Health Organisation's Workload Indicators of Staffing Need (WISN) methodology, a tworound Delphi consensus study with an Expert Panel of UK hospital pharmacy managers was undertaken to develop the Activity Standard for pharmaceutical care and to identify the time unavailable for clinical work inherent in employing staff. Consenting Panel members then tested the CPWC by calculating the staff resource required for three staffing scenarios to determine whether it could be reliably used by different operators.

\section{Results}

Thirty-six participants consented to participate, and data was returned from 22 participants (61\%) of whom $20(56 \%)$ supplied analysable data. Consensus was achieved on the tasks required for pharmaceutical care delivery, the mean time each takes, the frequency of completion and the unavailable time in the employment of each grade of staff identified. The CPWC uses this data in an algorithm to calculate staffing requirements. Eleven participants (55\%) tested the CPWC and analysis of their responses showed that 31 of $33(94 \%)$ calculations were accurately completed using the CPWC.

\section{Conclusion}

This study has defined the WISN Activity Standard for pharmaceutical care delivery to hospital inpatients and validated the CPWC for acute medical and surgical hospital settings. The CPWC offers hospital pharmacy managers a useful tool to negotiate adequate staffing to deliver pharmaceutical care and its development methodology could be applied widely in pharmacy practice internationally.

\section{Word counts}

Abstract: 300 words

Main body of text (excluding tables, figures and references): 2928 words

\section{Key words}

Clinical Pharmacy, Staffing, Workload

\section{Introduction}

The need to determine and manage appropriate staffing resource to be competitive and profitable has long been recognised in industry and commerce, and there is much for healthcare providers to learn from this. With a growing elderly population, increasing reliance on health services and limited resources, healthcare delivery is increasingly driven by cost containment and tight budgetary management. The challenge in terms of effective staff resource calculation to optimise productivity falls to all professions within healthcare and pharmacy is no exception.

The development of Clinical pharmacy services over the past 40 years has been largely based on the seminal paper by Hepler and Strand[1] on pharmacists' responsibility to deliver 'pharmaceutical care'. The objectives of these services have been clearly described as the management and prevention of medicines-related problems to achieve optimum health outcomes for individual patients, and the benefits of clinical pharmacy services have been demonstrated in terms of economic and patient safety outcomes[2-5]. However, much of the published literature on pharmacy staffing focuses on prioritisation of limited resources and productivity, mainly concentrating on dispensary services and supply functions, rather than the clinical aspects of pharmaceutical care[6,7]. Previous studies have determined hospital clinical pharmacy workforce requirements, based on tasks required for service delivery[8,9]. However, these estimates relied on a fixed number of 24 beds and an inpatient length of stay of 6 days, which limits their practical application to local scenarios with different patient throughput or service models.

In recent years there has been an increased focus on the Pharmacy workforce in the UK, particularly in reducing unwarranted variation, and identifying accurate baseline workforce requirements has become a priority [10]. It has been suggested that in order to be accepted into practice any healthcare workforce calculator tool needs to meet the four requirements of being simple to operate, adaptable to changing service 
delivery models, seen as valid by the healthcare practitioners and the outputs of it should be accepted and understood by non-clinicians[11]. The Clinical Pharmacy Workforce Calculator (CPWC) was initially developed from local time and motion studies of the tasks a group of senior pharmacists considered necessary for the delivery of care, the time the tasks routinely took pharmacists and the frequency with which local policy required them to be done. The resulting algorithm was simple to use since it required only the entry of bed numbers and average length of stay data to calculate the pharmacy staffing requirements of a ward-based service[12]. It was used to determine the pharmacist staffing needs of a series of new local service delivery initiatives and the CPWC output was accepted by senior hospital management. The next step then was for it to be validated by clinical pharmacists by more general application to other hospital pharmacy services, in different settings, which included considering its content validity and the reliability and consistency of its output[13]. The methodology adopted to do so is transferable to other settings and this report outlines a practical approach to addressing the issue of staffing levels for pharmacy practice.

\section{Aim}

This paper aims to critically report on the validation of the CPWC developed to determine the required staff resource for delivery of clinical pharmacy services for in-patients in acute hospitals.

\section{Ethics approval}

Institutional Ethical approval was obtained from Keele University.

\section{Method}

\section{Study design}

The World Health Organisation's (WHO) accepted methodology for determining healthcare staffing, the Workload Indicators of Staffing Need (WISN), was used as a theoretical framework for this study[14]. This has been applied in many healthcare settings internationally[15-17], but there are no published reports of its application to pharmacy services. Using the WISN approach required defining the 'Activity Standard' (i.e. the tasks and their times and frequencies) for clinical pharmacy service delivery (Figure 1).

WISN suggests that this should be a consensus of 'experts in the field' and so developing this consensus on the 'Activity Standard' for pharmaceutical care formed the primary aim of the study this paper reports on. This also involved establishing the amount of time when pharmacy staff do not undertake clinical activities, which is termed here as 'unavailable' time. A two-round Delphi study (a well-established method of developing consensus) [18-21] was undertaken to confirm the 'Activity Standard' for in-patient clinical pharmacy services and the 'unavailable' time for pharmacy staff. This was distributed and returned by email which facilitated a wide geographical response.

The second aim of the study was to establish the reliability of the tool through a subsequent 'operator evaluation'. This was completed by respondents from the Delphi study, again distributed and returned by email. Participants were provided with a copy of the CPWC, including instructions for use, and asked to use it to answer three hospital pharmacy staffing scenarios (shown in Table 1). Answers generated by participants were compared to identify whether a consistent response was achieved.

\section{Sampling and recruitment}

The target Delphi sample size was based on the literature, which suggests that consensus from participants with homogenous backgrounds can be achieved with samples of 10-15 participants [22]. Where heterogeneity of participants, or complexity of subject is increased, greater numbers are needed but these rarely exceed 50 participants[22]. The sample was anticipated to be relatively homogenous for pharmacy services in each health sector represented in the study, so the target was therefore 10-15 participants from each hospital sector e.g. acute trust, community hospital, mental health unit. Expert Panel participants were hospital pharmacy managers with strategic responsibilities for delivering pharmaceutical care in their setting, with permission from the Chief Pharmacist to share data within a specified timeframe. 
Invitations to participate were issued through regional and national professional forums, with a small number of personal invitations issued to individuals identified from professional networks. Where the inclusion criteria described above were met, no exclusion criteria were applied.

\section{Data collection}

For the first part of the study, consensus was electronically sought on the reference data in the CPWC algorithm. In Round one the Expert Panel was asked to identify from the locally-generated list of suggested 'clinical pharmacy tasks' those which they believed to be necessary for individual patient care, how long they perceived each task typically took (this could be provided as existing local data, data collected at the time to answer the question or 'best guess') and how often it would be necessary to complete each task for each patient admission. In addition, they were asked to identify for a range of staff groups the time in their employed hours that was typically unavailable for patient care. This included activities such as annual leave, sick leave, training, and travel. Round one responses were collated and anonymised and sent to each participant together with their own response in Round two for reconsideration in light of the Panel's collated responses. The Panel were asked additional questions in Round two to gain clarity on elements where consensus was not achieved in Round one, or where responses required conversion from narrative into numerical values to allow application in the algorithm. This was achieved by asking participants to respond to exemplar patient scenarios in terms of activities undertaken for patients by day of admission.

The second part of the study, the 'operator evaluation', was issued to the Delphi Panel participants. They were given instructions and asked to use the CPWC to calculate answers to the three staffing scenarios shown in table 1 and return them for analysis.

\section{Data analysis}

The data needed to determine the Activity Standard concerned the tasks required to deliver pharmaceutical care, the times these tasks should take and the frequency that they should be delivered. These data were analysed using descriptive statistics, using the mode value to identify consensus. The extent to which consensus was achieved was depicted using a 'RAG' rating (see Table 2) to give greater clarity on the strength of the consensus for each component, since there is no universal definition of consensus[21, 22]. This was particularly necessary where consensus was not reached for tasks to include in the CPWC, which then needed a finite value for the time taken to complete them and the frequency they should be undertaken for the algorithm in the CPWC to function. For times and frequencies associated with these tasks the typical binary approach of consensus/no-consensus was not practical. The RAG rating identified where agreement was widespread (green $>70 \%$ ) and where there were elements of greater variety of opinion (amber $>50 \%$ ). Where consensus (i.e. greater than $50 \%$ agreement on a specific figure) could not be achieved for the time a task took, the value for the algorithm was derived from the data provided. To be meaningful in calculating staffing levels nationally, these derived figures had to represent UK national practice and so the data was analysed by mean and median as well as mode to determine a 'national best representative' figure. Similarly, for the frequency of task completion where consensus was not achieved, especially for patient-dependent activities, responses from the exemplar patient questions in Round two were used to calculate an 'average' frequency for the purposes of algorithm development. To complete the WISN algorithm (Figure 1), the 'unavailable' staff time was calculated from a mean of reported data.

\section{Results}

In Round one 36 participants were recruited and responses were returned by $22(61 \%)$. Of these, one participant indicated that they were unable to provide data because their service delivery was so different the local 'suggested pharmacy tasks' did not apply. Another participant returned a corrupted electronic file and did not respond to requests to resend the data. Therefore analysable data was returned by 20 participants [56\%], but not all participants returned data for all questions. In Round 2 and the 'operator evaluation' the participation rate was $50 \%$ of the study population (11 participants).

\section{Demographics}


Of the 20 participants, eleven represented teaching hospitals, seven represented district general hospitals, one was from an intermediate care facility and one was from a mental health Trust. Participants were drawn from across Great Britain. Consensus sample size was therefore achieved i.e. greater than 10 participants for 'acute Trusts' and it is for this setting only that the validation of the CPWC has been conducted. Sample size for community hospitals and mental health units was not achieved. Staffing levels varied widely across the participant's sites, with teaching hospitals having around a third more staff for the equivalent bed base compared to district general hospitals.

\section{Identifying the activity 'standard' and unavailable time}

Over the two Rounds consensus was achieved for the tasks which are included in the CPWC and for the staff groups who need to complete them (see Table 3). Table 3 also shows that consensus was less certain for the time the tasks take and the frequency with which they should be done. The 'national best representative figure' derived for the timings from the data provided is shown in Table 4. The frequency of tasks for which consensus was not achieved were derived by calculating the mean frequency of activity for an 'average' patient from the responses participants provided to the management of exemplar patients questions. This pragmatic approach allowed the development of the CPWC and the strength of the data supporting each element is apparent in the presentation of the tool.

The proportion of each staff group's employed hours that the Panel identified as being unavailable for clinical/operational duties is shown in Table 5 and forms the 'unavailable time' data for the WISN algorithm.

\section{Operator evaluation and the transferability of the PWC}

Eleven of the 20 (55\%) participants completed the 'operator evaluation'. Analysis of their responses showed that by using the CPWC, participants consistently identified the same requirement for pharmacy staffing levels, in that 31 out of 33 calculations (94\%) were accurately completed using the CPWC.

\section{Discussion}

Consensus was identified for most elements of the CPWC through the Delphi process. Where consensus could not be achieved, data analysis identified a 'national best representative' figure instead. For several activities relating to the delivery of pharmaceutical care the consensus on frequency was that it depends on the patient'. This was explored in more detail by participants in round two of the Delphi study and allowed the generation of average frequencies of activities for the purposes of the CPWC being functional. The 'experts in the field' therefore contributed to determining the 'Activity Standard' for the WISN algorithm and in determining the 'unavailable' time for staff groups. The operator evaluation demonstrated the transferability of the CPWC to other operators, producing reliable and repeatable outputs.

The validity and reliability of a tool requires the consideration of a number of elements which are discussed in the context of the results of this study[13]. Content validity concerns the extent to which any tool addresses the full scope of the phenomenon being measured. This study achieved a national consensus on the tasks that are necessary for the delivery of pharmaceutical care, how long they take and how often they have to be performed, by which staff groups i.e. to establish an 'activity standard' for the delivery of pharmaceutical care. Content validity of the CPWC is therefore demonstrated through the consensus study data.

Two types of criterion validity are applicable to the CPWC; 'concurrent' and 'predictive'. Concurrent validity compares a tool with an existing 'gold standard'. The development of the CPWC followed the WISN[14] ] process and since this is the WHO 'gold standard' approach to calculation of workforce requirements, the CPWC could be considered a 'gold standard'. There are no current 'gold standard' calculations for pharmacy workforce resource, since the 1997 'Purkiss Model'[25] no longer reflects current workforce requirements. Direct comparison of the CPWC with more recent literature (post-2010)[8,9,26] requires presenting staffing requirement in terms of the number of beds per pharmacist. This comparison (see Table 6) demonstrated that the output of the CPWC matched two of the three reference sources [8,9]. Its advantage over this previous work is the practical development of a simple to use workforce calculator, which can be applied in practice. The outlier in the comparisons the figure identified from National Health Service benchmarking 2015/16[26]. 
This suggests that many sites are delivering services with far fewer staff than the Activity Standard would suggest. What is unknown is the difference in patient outcomes associated with these different staffing levels and further work is required to determine this.

Construct validity is demonstrated if outputs of some elements of the tool can be correlated with values calculated by different methods[13]. This is particularly important if the tool being validated is theoretically novel, which is directly relevant to the validation of the CPWC and this has been demonstrated in several ways. Many of the timings that drive the algorithm of the CPWC have construct validity in comparison with the literature [27-32]. This is particularly relevant for medicines reconciliation (MR), which is the single longest task that needs to be completed for pharmaceutical care. It also has the greatest influence on the value generated by the tool as it is required for all patients and is associated with reduction in patient harm from medicines[5].

The consistency and reproducibility of the data generated by a tool represents its reliability. The two relevant types of reliability are considered in the context of the CPWC, namely equivalence and stability. The tool has to produce consistent measurements in the hands of two or more investigators to demonstrate equivalence. The 'operator evaluation' in this study demonstrated equivalence between users of the CPWC.

The results of this study have validated the CPWC for application in acute general hospital in-patients only and this is acknowledged as a limitation of the study. Application in community or mental health in-patient settings has not been demonstrated due to insufficient participant numbers from these settings. Likewise, the CPWC is also not validated for use in specialties, such as critical care. However, this study does demonstrate the value of applying the WISN approach to pharmacy practice and with sector or specialityspecific adaptions to the Activity Standard, the CPWC could be applied to clinical pharmacy services to sectors such as mental health or specialisms such as critical care.

\section{Conclusion}

This report demonstrates that the CPWC is a validated tool for determining clinical pharmacy staffing requirements for medical and surgical inpatients in acute hospitals. We would further contend that it has demonstrated the four criteria of an acceptable staffing calculator, namely that it is simple to operate, adaptable to changing service delivery models, seen as valid by experts and its outputs accepted and understood by non-clinicians [11]. The methodology adopted to develop the CPWC is transferable to other settings and is a practical approach to addressing the issue of staffing levels for pharmacy practice internationally.

The process of validating the CPWC has generated a consensus-based description of the full scope of clinical pharmacy activities required to deliver pharmaceutical care to hospital in-patients and, therefore, sets a benchmark for future comparison. The CPWC does not identify 'safe' staffing levels, as that was not within the scope of this study. However, there is evidence from the literature that delivery of these tasks is associated with improved patient safety. Whilst not disputing that unwarranted variations exist in the delivery of healthcare within the UK, among other countries, the results of this study suggest the variation in pharmacy service provision is probably not located at what hospital pharmacy managers consider the fundamental principles of pharmaceutical care to be, but rather on how to deliver this care within the actual staff resource available.

\section{Funding}

This project was undertaken as a doctoral research project and no external funding was obtained.

\section{Conflicts of interest}

The authors declare that they have no competing interests.

\section{References}

1. Hepler C, Strand L. Opportunities and responsibilities in pharmaceutical care. Am J Hosp Pharm 1990; 47: 533-543. 
2. Bond C, Raehl C, Franke T. Interrelationships among mortality rates, drug costs, total cost of care, and length of stay in United States hospitals: summary and recommendations for clinical pharmacy services and staffing. Pharmacotherapy 2001 Feb; 21: 129-141.

3. Gallagher J, Byrne S, Woods N, Lynch D, McCarthy S. Cost-outcome description of clinical pharmacist interventions in a university teaching hospital. BMC Health Serv Res 2014; 14: 177.

4. Gammie T, Vogler S, Babar Z. Economic Evaluation of Hospital and Community Pharmacy Services: A Review of the Literature (2010-2015).Ann Pharmacother 2017; 51: 54- 65.

5. Bond C, Raehl C. Clinical pharmacy services, pharmacy staffing, and hospital mortality rates. Pharmacotherapy 2007; 27: 481-493.

6. Granko R, Poppe L, Savage S, Daniels R, Smith E, Leese P. Method to determine allocation of clinical pharmacist resources. Am J Health Syst Pharm 2012; 69: 1398-1404.

7. Acres S. How many staff members are needed to run a busy hospital dispensary? Pharm J 2004; 273 : 184.

8. O’Leary K, Stuchbery P, Taylor G. Clinical Pharmacist Staffing Levels Needed to Deliver Clinical Services in Australian Hospitals. J Pharm Prac Res 2010; 40: 217-221.

9. Onatade R, Miller G, Sanghera I. A quantitative comparison of ward-based clinical pharmacy activities in 7 acute UK hospitals.Int $J$ Clin Pharm 2016; 38: 1407-1415.

10. Lord Carter of Coles. Operational productivity and performance in English NHS acute hospitals: Unwarranted variations. An independent report for the Department of Health. 2016; Available at: https://www.gov.uk/government/publications/productivity-in-nhs-hospitals. Accessed 22/07/2020.

11. Schoo A, A Boyce R, Ridoutt L, Santos T. Workload capacity measures for estimating allied health staffing requirements. Aust Health Rev 2008; 32: 548-558.

12. Simcock V, Blackshaw C, Bednall R, Hanif I, Freeman S. What is the cost of a modern clinical pharmacy service? Part II - the development of a resource calculator. Conference Handbook UKCPA/GHP Joint Annual Conference. Manchester Abstract 51. 2014; Available at: http://ukclinicalpharmacy.org/community/our-library/. Accessed 22/07/2020.

13. Eddy D, Hollingworth W, Caro J, Tsevat J, McDonald K, Wong J. Model transparency and validation: A report of the ISPOR SMDM Modeling Good Research Practices Task Force-7. Value Health 2012; 15: 843-850.

14. World Health Organisation. Workload Indicators of staffing need [WISN] Users Manual. Geneva: 2015; Available at: http://www.who.int/hrh/resources/wisn_user_manual/en/. Accessed 22/07/2020.

15. McQuide P, Kolehmainen-Aitken R, Forster N. Applying the workload indicators of staffing need [WISN] method in Namibia: challenges and implications for human resources for health policy. Hum Resour Health 2013; 11: 64.

16. Hagopian A, Mohanty M, Das A, House P. Applying WHO's 'workforce indicators of staffing need' [WISN] method to calculate the health worker requirements for India's maternal and child health service guarantees in Orissa State. Health Policy Plan 2012; 27: 11-18.

17. World Health Organisation. Applying the WISN Method in Practice: Case studies from Indonesia, Mozambique and Uganda . 2010 Geneva: WHO Press: Available at http://www.who.int/hrh/resources/wisn_case_studies/en/. Accessed 22/07/2020.

18. Maskrey N, Underhill J. The European Statements of Hospital Pharmacy: achieving consensus using Delphi and World Cafe methodologies.Eur J Hosp Pharm 2014; 21: 264-266.

19. Jones J, Hunter D. Consensus methods for medical and health services research. Br Med J 1995; 311: 376-380.

20. Clyne W, White S, McLachlan S. Developing consensus-based policy solutions for medicines adherence for Europe: a Delphi study.BMC Health Serv Res 2012; 12: 425-6963-12-425.

21. von der Gracht, H. Consensus measurement in Delphi studies: Review and implications for future quality assurance. Technol Forecast Soc Change 2012 10; 79: 1525-1536.

22. Hsu CC, Sandford B. The Delphi technique: Making sense of consensus.Practical Assessment, Research and Evaluation 2007;12:1-8.

23. Suggett E, Marriott J. Electronic Risk Assessment as a Means of Directing a Clinical Pharmacy 
Service Conference Handbook, UKCPA Annual Conference, November 2016. 2016; Available at: http://ukclinicalpharmacy.org/community/our-library/. Accessed 22/07/2020.

24. Scott A. The productivity of the health workforce. Aust Econ Rev 2006; 39: 312-317.

25. Purkiss R. How to get the staff you need, calculation of pharmacy manpower requirements. Pharmacy in Practice 1997; 270: 393-396.

26. NHS Benchmarking Network. National Hospital Pharmacy Benchmarking Programme 2018-19. 2019; Available at https://s3.eu-west-2.amazonaws.com/nhsbnstatic/Pharmacy\%20\&\%20Medicines\%20Optimisation/2019/Summary\%20Report.pdf accessed $11 / 8 / 20$

27. Urban R, Armitage G, Morgan J, Marshall K, Blenkinsopp A, Scally A. Custom and practice: a multicenter study of medicines reconciliation following admission in four acute hospitals in the UK. Res Social Adm Pharm 2014; 10: 355-368.

28. Lizer M, Brackbill M. Medication history reconciliation by pharmacists in an inpatient behavioral health unit. Am J Health Syst Pharm 2007; 64: 1087-1091.

29. Nester T, Hale L. Effectiveness of a pharmacist-acquired medication history in promoting patient safety. Am J Health Syst Pharm2002; 59: 2221-2225.

30. Jenkins A, Eckel S. Analyzing methods for improved management of workflow in an outpatient pharmacy setting. Am J Health Syst Pharm 2012; 69: 966-971.

31. Calabrese S, Williams J. Implementation of a web-based medication tracking system in a large academic medical center. Am J Health Syst Pharm 2012; 69: 1651-1658.

32. Stuchberry P, Kong D, DeSantis G, Lo S. Clinical pharmacy workload in medical and surgical patients: effect of patient partition disease complexity and Major Disease Category. Int J Pharm Pract 2010; 18: $159-166$.

\section{Figures and Tables}

Figure 1. WISN algorithm

Staff resource $=$ Time to perform role for full patient population Available working time Time to perform role $=$ Activity st

Table 1. Scenarios given to pharmacy managers

\section{Scenario 1}

A new general medical ward is planned to open. This will have 28 beds and an average length of stay of 5 days. The averag Scenario 2

An existing 28 bed general medical ward with average length of stay of 4 days (average items 8 ) is being converted to a sho Scenario 3

Finally, you are approached by a directorate manager about to submit a business case for 200 new bariatric surgical patient

Table 2. RAG rating of establishment of consensus

\begin{tabular}{lll}
\hline Level of consensus & $\%$ of participants in agreement & RAG \\
\hline Strong & 70 or greater \\
Moderate & $50-69$ & \\
None & $<50$ \\
\hline
\end{tabular}

Table 3. Consensus on the 'Activity Standard' for clinical pharmacy 


\begin{tabular}{|c|c|c|c|c|c|}
\hline $\begin{array}{l}\text { Direct patient } \\
\text { care activities } \\
\text { completed for } \\
\text { each patient } \\
\text { admission }\end{array}$ & $\begin{array}{l}\% \text { Agreement } \\
\text { with task } \\
\text { necessity } n=20\end{array}$ & $\begin{array}{l}\text { Staff group } \\
\text { required to } \\
\text { deliver task. } \\
\text { Mode response } \\
(\%) n=20\end{array}$ & $\begin{array}{l}\text { Mean time task } \\
\text { takes in minutes. } \\
\text { Mode response } \\
(\% \text { and range })\end{array}$ & $\begin{array}{l}\text { Frequency which } \\
\text { task should be } \\
\text { done for each } \\
\text { patient } \\
\text { admission. Mode } \\
\text { response (\% } \\
\text { agreement \& } \\
\text { range) }\end{array}$ & \\
\hline $\begin{array}{l}\text { Medicines } \\
\text { Reconciliation } \\
\text { (pharmacy } \\
\text { confirmed and } \\
\text { signed off) }\end{array}$ & $\begin{array}{l}\text { Medicines } \\
\text { Reconciliation } \\
\text { (pharmacy } \\
\text { confirmed and } \\
\text { signed off) }\end{array}$ & 100 & $\begin{array}{l}\mathrm{P} / \mathrm{MMT}= \\
81 \%\end{array}$ & $\begin{array}{l}\mathrm{n}=2010(29 \%) \\
\& 20(29 \%) 6-30\end{array}$ & $\mathrm{n}=20 \quad 1(85 \%) \quad 1-2$ \\
\hline $\begin{array}{l}\text { Check of } \\
\text { Patients Own } \\
\text { Drugs (PODs) }\end{array}$ & $\begin{array}{l}\text { Check of } \\
\text { Patients Own } \\
\text { Drugs (PODs) }\end{array}$ & 95 & $\mathrm{MMT}=91 \%$ & $\begin{array}{l}\mathrm{n}=175(58 \%) \\
4-15\end{array}$ & $\mathrm{n}=201(65 \%) \quad 1-2$ \\
\hline $\begin{array}{l}\text { Clinical } \\
\text { Review of } \\
\text { Notes }\end{array}$ & $\begin{array}{l}\text { Clinical } \\
\text { Review of } \\
\text { Notes }\end{array}$ & 90 & $\mathrm{P}=81 \%$ & $\begin{array}{l}\mathrm{n}=185(66 \%) \\
2-10\end{array}$ & $\begin{array}{l}\mathrm{n}=20 \\
\text { "Depends" } \\
(45 \%) \text { Daily - } \\
7\end{array}$ \\
\hline $\begin{array}{l}\text { Review of } \\
\text { Blood results }\end{array}$ & $\begin{array}{l}\text { Review of } \\
\text { Blood results }\end{array}$ & 90 & $\mathrm{P}=81 \%$ & $\begin{array}{l}\mathrm{n}=175(35 \%) \\
1-5\end{array}$ & $\begin{array}{l}\mathrm{n}=19 \\
\text { "Depends" } \\
(52 \%) \\
\text { Depends-3 }\end{array}$ \\
\hline $\begin{array}{l}\text { Initial review } \\
\text { of Drug Chart } \\
\text { Initial } \\
\text { endorsing of } \\
\text { Drug Chart }\end{array}$ & $\begin{array}{l}\text { Initial review } \\
\text { of Drug Chart } \\
\text { Initial } \\
\text { endorsing of } \\
\text { Drug Chart }\end{array}$ & $\begin{array}{l}100 \\
95\end{array}$ & $\begin{array}{l}\mathrm{P}=81 \% \\
\mathrm{P}=91 \%\end{array}$ & $\begin{array}{l}\mathrm{n}=185(50 \%) \\
2-5 \\
\mathrm{n}=175(40 \%) \\
1-10\end{array}$ & $\begin{array}{l}\mathrm{n}=191(79 \%) \\
\text { Depends-1 } \\
\mathrm{n}=171(82 \%) \\
\text { Depends-1 }\end{array}$ \\
\hline $\begin{array}{l}\text { Subsequent } \\
\text { review of Drug } \\
\text { Chart }\end{array}$ & $\begin{array}{l}\text { Subsequent } \\
\text { review of Drug } \\
\text { Chart }\end{array}$ & 95 & $\mathrm{P}=90 \%$ & $\begin{array}{l}\mathrm{n}=175(41 \%) \\
1-5\end{array}$ & $\begin{array}{l}\mathrm{n}=18 \\
\text { "Depends" } \\
(44 \%)\end{array}$ \\
\hline $\begin{array}{l}\text { Subsequent } \\
\text { endorsing of } \\
\text { Drug Chart } \\
\text { Completion of } \\
\text { Paperwork } \\
\text { (Pharmacy } \\
\text { handover/care } \\
\text { plans etc) }\end{array}$ & $\begin{array}{l}\text { Subsequent } \\
\text { endorsing of } \\
\text { Drug Chart } \\
\text { Completion of } \\
\text { Paperwork } \\
\text { (Pharmacy } \\
\text { handover/care } \\
\text { plans etc) }\end{array}$ & 86 & $\begin{array}{l}\mathrm{P}=61 \% \\
\mathrm{MMT}=52 \%\end{array}$ & $\begin{array}{l}\mathrm{n}=172(30 \%) \\
0-5 \\
\mathrm{n}=95(66 \%) 1-5\end{array}$ & $\begin{array}{l}\text { Depends-Daily } \\
\mathrm{n}=17 \text { "Depends" } \\
(41 \%) \\
\text { Depends-daily } \\
\mathrm{n}=11 \text { "Depends" } \\
(27 \%) \\
\text { Depends-Daily }\end{array}$ \\
\hline $\begin{array}{l}\text { Ordering of Non } \\
\text { Stocks }\end{array}$ & $\begin{array}{l}\text { Ordering of Non } \\
\text { Stocks }\end{array}$ & 90 & & $\begin{array}{l}\mathrm{n}=165(44 \%) \\
1-5\end{array}$ & $\begin{array}{l}n=17 \text { "Depends" } \\
(47 \%) \text { Depends-3 }\end{array}$ \\
\hline $\begin{array}{l}\text { Clinical Check of } \\
\text { Discharge } \\
\text { prescription }\end{array}$ & $\begin{array}{l}\text { Clinical Check of } \\
\text { Discharge } \\
\text { prescription }\end{array}$ & 100 & $\mathrm{P}=76 \%$ & $\begin{array}{l}\mathrm{n}=20 \quad 5(38 \%) \\
2-17\end{array}$ & $\mathrm{n}=201(100 \%)$ \\
\hline $\begin{array}{l}\text { Talking to } \\
\text { patient about } \\
\text { their medicines }\end{array}$ & $\begin{array}{l}\text { Talking to } \\
\text { patient about } \\
\text { their medicines }\end{array}$ & 95 & $\mathrm{P} / \mathrm{MMT}=81 \%$ & $\begin{array}{l}\mathrm{n}=175(47 \%) \\
1-15\end{array}$ & $\begin{array}{l}\mathrm{n}=17(40 \%) \\
\text { Depends-2 }\end{array}$ \\
\hline
\end{tabular}




\begin{tabular}{|c|c|c|c|c|c|}
\hline $\begin{array}{l}\text { Direct patient } \\
\text { care activities } \\
\text { completed for } \\
\text { each patient } \\
\text { admission }\end{array}$ & $\begin{array}{l}\% \text { Agreement } \\
\text { with task } \\
\text { necessity } n=20\end{array}$ & $\begin{array}{l}\text { Staff group } \\
\text { required to } \\
\text { deliver task. } \\
\text { Mode response } \\
(\%) n=20\end{array}$ & $\begin{array}{l}\text { Mean time task } \\
\text { takes in minutes. } \\
\text { Mode response } \\
\text { (\% and range) }\end{array}$ & $\begin{array}{l}\text { Frequency which } \\
\text { task should be } \\
\text { done for each } \\
\text { patient } \\
\text { admission. Mode } \\
\text { response (\% } \\
\text { agreement \& } \\
\text { range) }\end{array}$ & \\
\hline $\begin{array}{l}\text { Making } \\
\text { interventions } \\
\text { on patient care }\end{array}$ & $\begin{array}{l}\text { Making } \\
\text { interventions } \\
\text { on patient care }\end{array}$ & 100 & $\mathrm{P}=100 \%$ & $\begin{array}{l}\mathrm{n}=165(56 \%) \\
1-10\end{array}$ & $\begin{array}{l}\mathrm{n}=19 \\
\text { "Depends" } \\
(57 \%) \\
\text { Depends-Daily }\end{array}$ \\
\hline Key: & Key: & Key: & Key: & Key: & Key: \\
\hline $\mathrm{P}=$ pharmacist & $\mathrm{P}=$ pharmacist & $\mathrm{P}=$ pharmacist & $\mathrm{P}=$ pharmacist & $\mathrm{P}=$ pharmacist & $\mathrm{P}=$ pharmacist \\
\hline $\begin{array}{l}\text { MMT=medicines } \\
\text { management } \\
\text { technician }\end{array}$ & $\begin{array}{l}\mathrm{MMT}=\text { medicines } \\
\text { management } \\
\text { technician }\end{array}$ & $\begin{array}{l}\text { MMT=medicines } \\
\text { management } \\
\text { technician }\end{array}$ & $\begin{array}{l}\text { MMT=medicines } \\
\text { management } \\
\text { technician }\end{array}$ & $\begin{array}{l}\mathrm{MMT}=\text { medicines } \\
\text { management } \\
\text { technician }\end{array}$ & $\begin{array}{l}\text { MMT=medicines } \\
\text { management } \\
\text { technician }\end{array}$ \\
\hline $\begin{array}{l}\text { PODs=patient's } \\
\text { own drugs }\end{array}$ & $\begin{array}{l}\text { PODs=patient's } \\
\text { own drugs }\end{array}$ & $\begin{array}{l}\text { PODs=patient's } \\
\text { own drugs }\end{array}$ & $\begin{array}{l}\text { PODs=patient's } \\
\text { own drugs }\end{array}$ & $\begin{array}{l}\text { PODs=patient's } \\
\text { own drugs }\end{array}$ & $\begin{array}{l}\text { PODs=patient's } \\
\text { own drugs }\end{array}$ \\
\hline $\begin{array}{l}\mathrm{P} / \mathrm{MMT}= \\
\text { pharmacists or } \\
\text { MMTs "de- } \\
\text { pends" = depends } \\
\text { on patient } \\
\text { characteristics }\end{array}$ & $\begin{array}{l}\mathrm{P} / \mathrm{MMT}= \\
\text { pharmacists or } \\
\text { MMTs "de- } \\
\text { pends"=depends } \\
\text { on patient } \\
\text { characteristics }\end{array}$ & $\begin{array}{l}\mathrm{P} / \mathrm{MMT}= \\
\text { pharmacists or } \\
\text { MMTs "de- } \\
\text { pends" =depends } \\
\text { on patient } \\
\text { characteristics }\end{array}$ & $\begin{array}{l}\mathrm{P} / \mathrm{MMT}= \\
\text { pharmacists or } \\
\text { MMTs "de- } \\
\text { pends" =depends } \\
\text { on patient } \\
\text { characteristics }\end{array}$ & $\begin{array}{l}\mathrm{P} / \mathrm{MMT}= \\
\text { pharmacists or } \\
\text { MMTs "de- } \\
\text { pends" = depends } \\
\text { on patient } \\
\text { characteristics }\end{array}$ & $\begin{array}{l}\mathrm{P} / \mathrm{MMT}= \\
\text { pharmacists or } \\
\text { MMTs "de- } \\
\text { pends" =depends } \\
\text { on patient } \\
\text { characteristics }\end{array}$ \\
\hline
\end{tabular}

Table 4. Identification of time required to complete tasks

\begin{tabular}{lll}
\hline Data type & Time in minutes required to complete task & Time in minutes required to \\
\hline & $\mathrm{MR}$ & POD check \\
PWC study version & 20 & 5 \\
n (all data) & 18 & 17 \\
Mean time (all data) & 17.61 & 6.53 \\
St Dev (all data) & 6.71 & 2.96 \\
Mode (all data) & 20 & 5 \\
Mode count & 6 & 11 \\
Mode \% consensus & 33.33 & 64.71 \\
Median & 20 & 5 \\
Minimum & 10 & 4 \\
Maximum & 30 & 15 \\
ELD n & 8 & $\mathrm{NA}$ \\
Mean time (ELD) & 20 & $\mathrm{NA}$ \\
ST DEV (ELD) & 8.05 & \\
National 'best representative' figure & 20 & 5 \\
\hline
\end{tabular}

Key: $n=$ number of participants providing data ELD = existing local data supplied by participants

Table 5. Mean staff time 'unavailable' for clinical/operational duties

\section{Hosted file}


image1.emf available at https://authorea.com/users/351964/articles/476363-validation-of-ahospital-clinical-pharmacy-workforce-calculator-a-methodology-for-pharmacy

Table 6. Comparison of workforce requirements from recent literature

\begin{tabular}{ll}
\hline Reference source & Beds/WTE pharmacist \\
\hline $\begin{array}{l}\text { O'leary, Stuchberry \& Taylor[8] (Average hospital- } \\
\text { wide, average LOS 6 days) }\end{array}$ & 19.5 \\
Onatade, Miller \& Sanghera[9] (average across 7 & 18.19 \\
London sites) & 43 \\
NHS Benchmarking[26] & 22 \\
RSPWC (24 bed ward, LOS 6 days, 5 day service) & 22 \\
\hline
\end{tabular}

